\title{
Effect of Enzyme Type on the Control of Fluorescent Whitening Agents during Recycling
}

\author{
Hae Min Jo, ${ }^{a}$ Ji Young Lee, ${ }^{\text {, } *}$ Su Ho Kim,,${ }^{a}$ Yeon Hui Lee, ${ }^{a}$ and Chul Hwan Kim ${ }^{b}$
}

\begin{abstract}
The goal of this study was to develop an eco-friendly removal technology for fluorescent whitening agents (FWAs) using enzymes suitable for each type of FWA. Internally treated paper with internal FWA (D-FWA) and surface-sized paper with surface-sizing FWA (T-FWA) were made as model papers in a laboratory. The enzymatic treatments were applied to the stock prepared using these model papers by disintegration. Cellulase and (alpha-) amylase treatments were performed at $50{ }^{\circ} \mathrm{C}$ under the conditions of $\mathrm{pH} 3$ to 4 and $\mathrm{pH} 7$ to 8 , respectively. After disintegration and enzymatic treatments, handsheets were made, and the fluorescence index and FWA reduction of these handsheets were determined for evaluating FWA removal during recycling. Because D-FWA gets strongly attached to cellulosic fibers, it could not be easily separated from the internally treated paper by disintegration. Up to $8.1 \%$ of D-FWA was removed by enzymatic treatment with high-activity cellulase. Amylase could not separate D-FWA from cellulosic fibers. In the case of T-FWA, ca. $41 \%$ was separated by disintegration, and an additional $24 \%$ was detached from surface-sized papers by high-activity amylase treatment. Therefore, cellulase was effective in removing internal FWA (D-FWA), and amylase was required for removing surface-sizing FWA (T-FWA) during recycling.
\end{abstract}

Keywords: Fluorescent whitening agent; Removal; Recycling; Cellulase; Alpha-amylase; Fluorescence index

Contact information: a: Department of Forest Products; $b$ : Department of Environmental Materials Science/IALS, Gyeongsang National University, Jinju 52828, Republic of Korea;

*Corresponding author: paperyjy@gnu.ac.kr

\section{INTRODUCTION}

In the paper industry, many types of dyes are used to improve the appearance of paper and to satisfy the demands of consumers (Shadkami et al. 2011; Lee et al. 2012; Zhao et al. 2020). Among these dyes, fluorescent whitening agents (FWAs) are used for producing paper with high whiteness. With the increase in demand for such paper among Korean consumers, the amount of FWA used has increased steadily.

Recycled paper is an extremely important resource in the Korean paper industry. Many types of recycled papers are used for producing other types of paper, such as packaging papers, newsprint, and tissues (Dainelli 2008; Presas and Pesonen 2013). Among these recycled papers, high-whiteness paper is the most important resource. However, the amount of recycled white paper is limited because it contains FWAs, which can be a problem according to the laws (Jiang et al. 2015). In addition, many consumers have considered FWAs to be toxic, despite the lack of clear evidence for this assessment (Kim et al. 2017). Considering that the pulp self-sufficiency rate of the Korean paper industry is lower than in other countries (Jeong 2016), it is necessary to develop a technology capable of effectively controlling FWAs in the recycling process in order to maximize the amount of high-whiteness paper.

Some technologies for removing or quenching FWAs from recycled white papers 
have been reported. For example, the use of a strong oxidizing agent (Lakowicz and Weber 1973) and ozone treatment (Buschmann 2018) were suggested to break down FWAs during recycling as these treatments can destroy or change the molecular structure of FWAs. However, the utilization of oxidizing agents has been limited due to the regulations that restrict discharge of chlorinated waste (Pauksta 1995) and the ozone treatment is impractical in an actual mill. This is because ozone treatment can corrode machines and consume a large amount of energy for temperature control and cooling (Lee 2009). Moreover, some dyes are resistant to ozone and require high ozone doses (Crini and Lichtfouse 2018). Therefore, there is a need for an eco-friendly and viable technology for controlling FWAs during recycling.

In a previous study, a technique for controlling FWAs using enzymes was proposed (Lee et al. 2008). Commercial enzymes were applied to evaluate the separation of FWAs from commercial fine paper, and the possibility of enzyme application was suggested. However, the possibility of applying specific enzymes according to the type of FWA was not explored. For realizing an effective eco-friendly FWA control technology using enzymes during recycling, it is necessary to select a suitable enzyme for each type of FWA because the materials to which FWAs bind and their distribution within the paper are different according to the type of FWAs.

In this study, FWAs were classified into two groups, namely, internal FWA (disulfo FWA; D-FWA) and surface-sizing FWA (tetrasulfo FWA; T-FWA) (Perng et al. 2015; Kim et al. 2017). Two types of model papers were prepared - internally treated paper with D-FWA and surface-sized paper with T-FWA. Considering the functionality of commercial enzymes, cellulase and alpha-amylase (amylase) were used for the enzymatic treatment of each type of paper during recycling. The fluorescence index of the handsheets and fluorescence emission of stock supernatant were measured to calculate FWA reduction and to determine FWA removal from model papers after disintegration and enzymatic treatment. Using this information, the enzyme suitable for removing the given type of FWA was identified.

\section{EXPERIMENTAL}

\section{Materials}

D-FWA and T-FWA were purchased from Kyung-In Synthetic Corporation (Seoul, Republic of Korea). Bleached softwood kraft pulp (Sw-BKP) and bleached hardwood kraft pulp (Hw-BKP), which were supplied by Moorim Paper (Jinju, Republic of Korea), were used to make handsheets dyed with D-FWA. Never-sized fine paper with a grammage of $95 \mathrm{~g} / \mathrm{m}^{2}$ was used as the base paper for surface sizing with T-FWA and oxidized starch supplied by Dasesang Co. Ltd. (Seoul, Republic of Korea). Two types of cellulases and two types of amylases, supplied by Novozymes A/S (Copenhagen, Denmark), were used to remove FWAs from the model papers. Table 1 lists the specifications of each enzyme. 
Table 1. Specifications of Commercial Enzymes Used in this Study

\begin{tabular}{|c|c|c|c|c|}
\hline Enzyme & Cellulase 1 & Cellulase 2 & Amylase 1 & Amylase 2 \\
\hline Declared enzyme & \multicolumn{2}{|c|}{ Cellulase } & \multicolumn{2}{c|}{ Amylase } \\
\hline Commercial name & $\begin{array}{c}\text { Cellusoft } \\
25000 \mathrm{~L}\end{array}$ & $\begin{array}{c}\text { Novozyme } \\
50199\end{array}$ & $\begin{array}{c}\text { Aquazym } \\
240 \mathrm{~L}\end{array}$ & $\begin{array}{c}\text { Aquazym } \\
480 \mathrm{~L}\end{array}$ \\
\hline Declared activity & $25,000 \mathrm{BPU} / \mathrm{g}$ & $\begin{array}{c}1,000 \\
\mathrm{BHU}-2 / \mathrm{g}\end{array}$ & $240 \mathrm{KNU} / \mathrm{g}$ & $480 \mathrm{KNU} / \mathrm{g}$ \\
\hline $\begin{array}{c}\text { Operational range of } \mathrm{pH} \\
\begin{array}{c}\text { Operational range of } \\
\text { temperature }\end{array}\end{array}$ & $4.5-6.5$ & $4.5-6.0$ & $5.5-8.0$ & $4.5-7.5$ \\
\hline
\end{tabular}

* Activity given by the suppliers' data sheets (BPU: One protease unit, BHU-2: A biomass hydrolysis unit, KNU: One kilo novo alpha-amylase unit)

\section{Methods}

Preparation of FWA solutions and handsheets containing D-FWA

D-FWA and T-FWA were dissolved in distilled water with vigorous mixing to prepare $0.1 \%$ solutions. Hw-BKP and Sw-BKP were beaten to $450 \pm 5 \mathrm{~mL}$ (Canadian Standard Freeness; CSF) using a laboratory Hollander beater (Daeil Machinery Co. Ltd, Daejeon, Republic of Korea). The pulp samples were mixed in a ratio of $8: 2$ (HwBKP:SwBKP). The mixed pulp slurry was then diluted to a $0.5 \%$ consistency for preparing the handsheets. Handsheets with a grammage of $100 \pm 5 \mathrm{~g} / \mathrm{m}^{2}$ were produced according to TAPPI T205 sp-06 (2006) after adding 1.0\% of D-FWA on oven-dried fibers to the pulp slurry and mixing for $2 \mathrm{~min}$ at $600 \mathrm{rpm}$. The handsheets were wet-pressed at $345 \mathrm{kPa}$ for 5 min using a laboratory wet press (Model 326, Wintree Corporation, Osaka, Japan) and then dried at $120^{\circ} \mathrm{C}$ using a cylinder dryer (Daeil Machinery Co. Ltd, Daejeon, South Korea). The prepared handsheets were conditioned at $23{ }^{\circ} \mathrm{C}$ and $50 \% \mathrm{RH}$ and then used for the experiments.

Surface sizing of base paper with a starch solution including T-FWA

The starch solution was prepared and surface sizing was performed as described previously (Kim et al. 2017; Lee et al. 2015). The starch solution (concentration: 10\%) was prepared by cooking oxidized starch at $90{ }^{\circ} \mathrm{C}$ to $95^{\circ} \mathrm{C}$ for $30 \mathrm{~min}$. After the temperature of the starch solution was set to $50{ }^{\circ} \mathrm{C}, 10 \%$ T-FWA of oven-dried starch was added, and the resulting solution was mixed for $30 \mathrm{~min}$. The surface-sizing process was performed using a rod coater (HT-BC-ST, Hantech, Daejeon, Korea). The top side of a never-sized paper was surface sized, and the paper was dried in an air dryer for $150 \mathrm{~s}$. To prevent curling of the surface-sized paper, it was passed through a cylinder dryer twice at $120{ }^{\circ} \mathrm{C}$. After the top side of the base paper was surface sized, the bottom side of the paper was subjected to the same treatment. The final pickup weight was controlled at 2.0 to $2.5 \mathrm{~g} / \mathrm{m}^{2}$ for each side. Before measuring the optical properties, the surface-sized paper was conditioned at $23{ }^{\circ} \mathrm{C}$ and $50 \%$ relative humidity. Figure 1 shows the flow diagram of the preparation of model papers containing FWAs (Lee et al. 2015). 
(a)

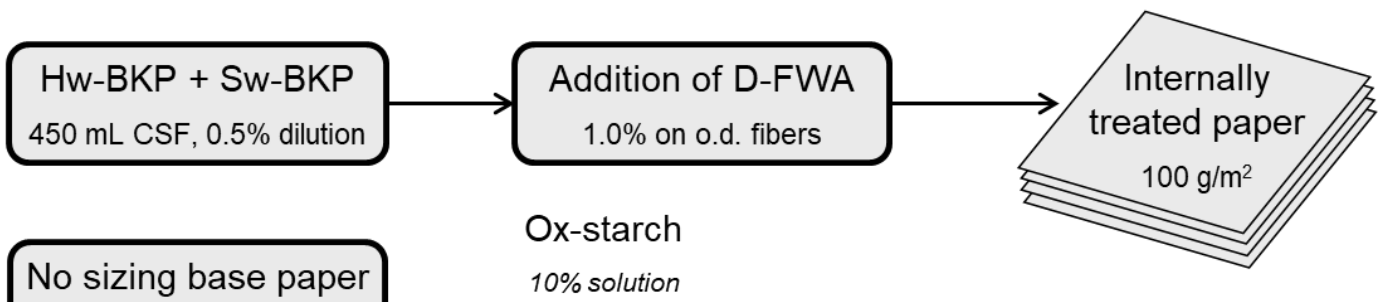

(b)

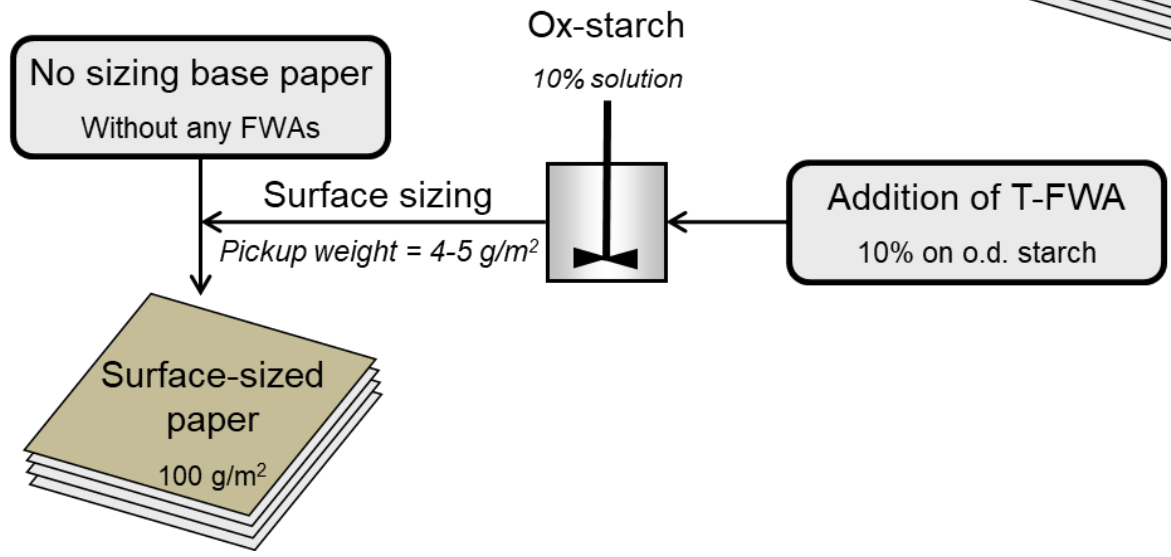

Fig. 1. Preparation of model papers dyed with (a) D-FWA and (b) T-FWA

Evaluation of $F W A$ reduction from model papers using enzymes

The disintegration of model papers dyed with FWAs was carried out at a consistency of $2 \%$ level using a laboratory disintegrator (Daeil Machinery Co., Ltd.); subsequently, the $\mathrm{pH}$ of the stock was adjusted differently as shown in Table 2 according to the enzyme specifications. Thereafter, $0.5,1.0$, or $1.5 \% \mathrm{w} / \mathrm{w}$ enzymes of oven-dried fibers were added into the stock. After the addition of enzymes, the stock was stirred at 600 $\mathrm{rpm}$ and $50^{\circ} \mathrm{C}$ for $30 \mathrm{~min}$. After enzyme treatment for $30 \mathrm{~min}$, handsheets with a grammage of $100 \pm 5 \mathrm{~g} / \mathrm{m}^{2}$ were produced, wet-pressed at $345 \mathrm{kPa}$ for $5 \mathrm{~min}$, and dried at $120^{\circ} \mathrm{C}$ in a laboratory wet press and a cylinder dryer. The handsheets were conditioned at $23{ }^{\circ} \mathrm{C}$ and $50 \% \mathrm{RH}$; then, the fluorescence index was measured. The fluorescence index was determined from the International Commission on Illumination (CIE) whiteness measurements under a D65 illuminant. The supernatant of the stock was also obtained by filtering through a Büchner funnel after enzyme treatment. The fluorescence emission of the supernatant was measured to identify the removed FWAs using a fluorophotometer (Luminescence spectrophotometer, PerkinElmer, Waltham, USA). The excitation and emission wavelengths were $370 \mathrm{~nm}$ and $440 \mathrm{~nm}$, respectively.

Table 2. Conditions of Enzyme Treatments

\begin{tabular}{|c|c|c|c|c|}
\hline Enzyme & Cellulase 1 & Cellulase 2 & Amylase 1 & Amylase 2 \\
\hline $\mathrm{pH}$ & $3-4$ & $3-4$ & $7-8$ & $7-8$ \\
\hline Addition level & \multicolumn{4}{|c|}{$0.5 / 1.0 / 1.5 \%$ on oven-dried fibers } \\
\hline
\end{tabular}




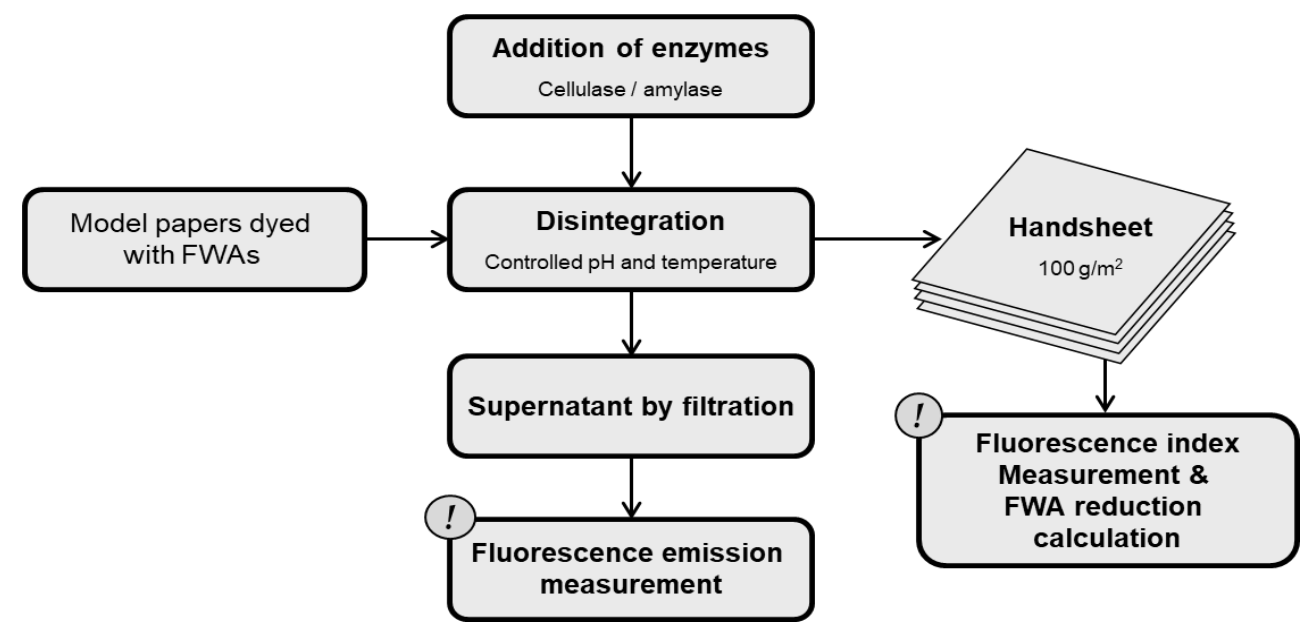

Fig. 2. Flow diagram of the evaluation of enzymatic removal of FWAs from model papers

The FWA reduction from model papers dyed with FWAs was calculated as an indicator that represents the FWA detachment from the paper by using the fluorescence indices before and after enzymatic treatments (Lee et al. 2019).

$$
\text { FWA reduction }=\frac{\mathrm{FI}_{\text {before }}-\mathrm{FI}_{\text {after }}}{\mathrm{FI}_{\text {before }}} \times 100
$$

where $\mathrm{FI}_{\text {before }}$ is the initial fluorescence index of the model paper (CIE whiteness under D65 illumination before disintegration and any enzymatic treatment), and $\mathrm{FI}_{\text {after }}$ is the fluorescence index of the handsheet (CIE whiteness under D65 illumination after disintegration and specified levels of enzymatic treatment).

\section{RESULTS AND DISCUSSION}

\section{FWA Removal from Two Model Papers Using Cellulase}

Cellulase has tremendous potential for application in the pulp and paper industry. Commercial cellulase can be utilized for improving the pulp yield, fiber properties, paper recycling, and energy efficiency and for reducing process and environmental problems (Lee et al. 1982; Rahikainen et al. 2019). In this study, the applicability of cellulase to remove two types of FWAs from model papers was evaluated. Figure 3 shows the fluorescence index and FWA reduction of the handsheets made from internally treated paper after disintegration and cellulase treatment. Here, control indicates the internally treated model paper with $1 \%$ D-FWA. The initial fluorescence index of the internally treated paper was about $51 \%$ and that of the handsheet after disintegration was about $50 \%$. As increasing amounts of cellulase were added, the fluorescence index of the handsheets decreased linearly. A comparison of the two types of cellulases showed that for the same amount of cellulase added, cellulase 1 with higher activity resulted in a lower fluorescence index of the handsheets. FWA reduction increased as a function of the addition of cellulase, and the maximum FWA reduction was $8.1 \%$ for $1.5 \%$ cellulase 1 and $2.6 \%$ for $1.5 \%$ cellulase 2 , respectively. There was little difference between the fluorescence indices of the internally treated paper and handsheet after disintegration, implying that D-FWA did not easily separate from the internally treated paper by mechanical action alone. Such findings are consistent with Rahikainen et al. (2019), who reported that FWA becomes strongly attached to cellulosic fibers. Figure 4 shows the fluorescence emission of the supernatant after disintegration and cellulase treatment. 

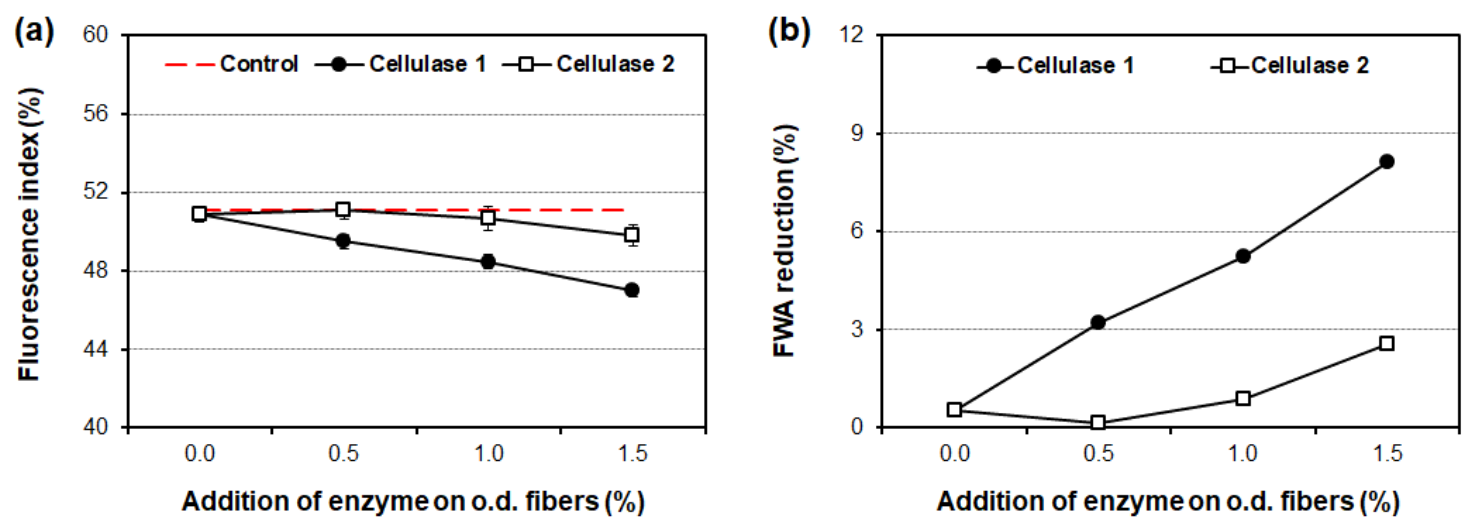

Fig. 3. Fluorescence index (a) and FWA reduction (b) of the handsheet made from internally treated paper with D-FWA after disintegration and cellulase treatment (where control indicates the internally treated model paper with $1 \% \mathrm{D}-\mathrm{FWA}$ )

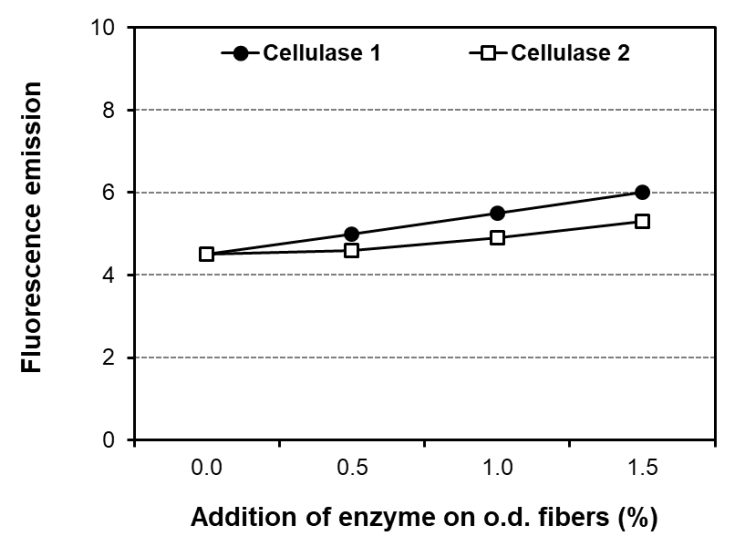

Fig. 4. Fluorescence emission of the supernatant from the internally treated paper with D-FWA after disintegration and cellulose treatment

As more cellulase was added, the fluorescence emission of the supernatant increased because the detached D-FWA from the cellulosic fiber was dissolved in the supernatant, and the amount of D-FWA in the supernatant increased as a function of cellulase addition. Thus, the fluorescence emission result agreed with the FWA reduction results. Based on these data, cellulase can attack the fiber surface and separate a portion of the fiber surface such as fines or fibrils, thereby removing the D-FWA adsorbed on the fiber surface, as shown in Fig. 5.

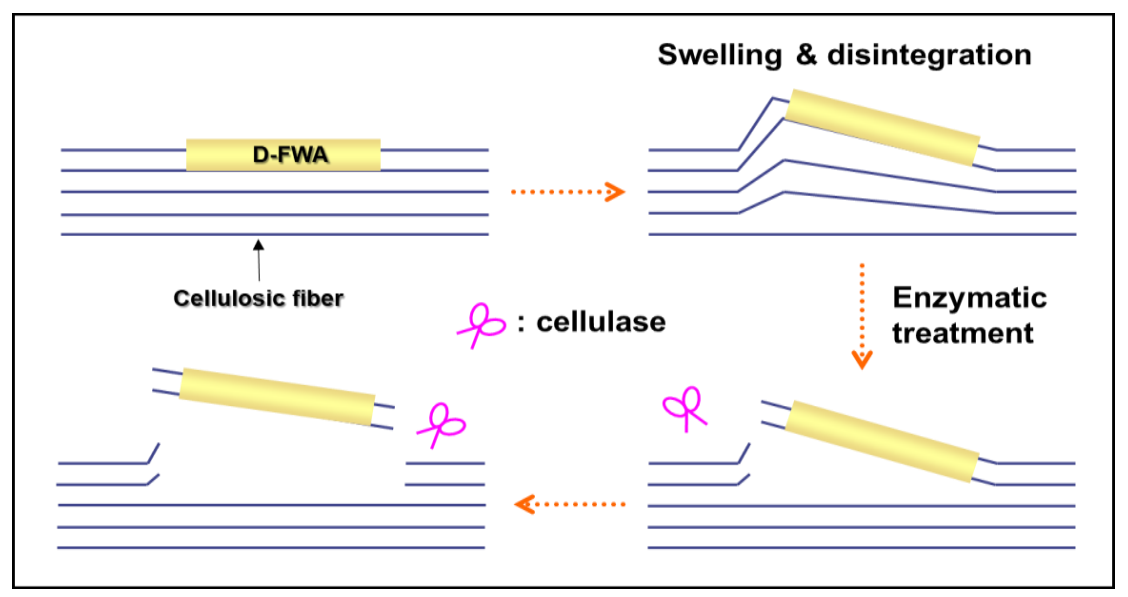

Fig. 5. Mechanism of D-FWA detachment from cellulosic fiber using cellulase 

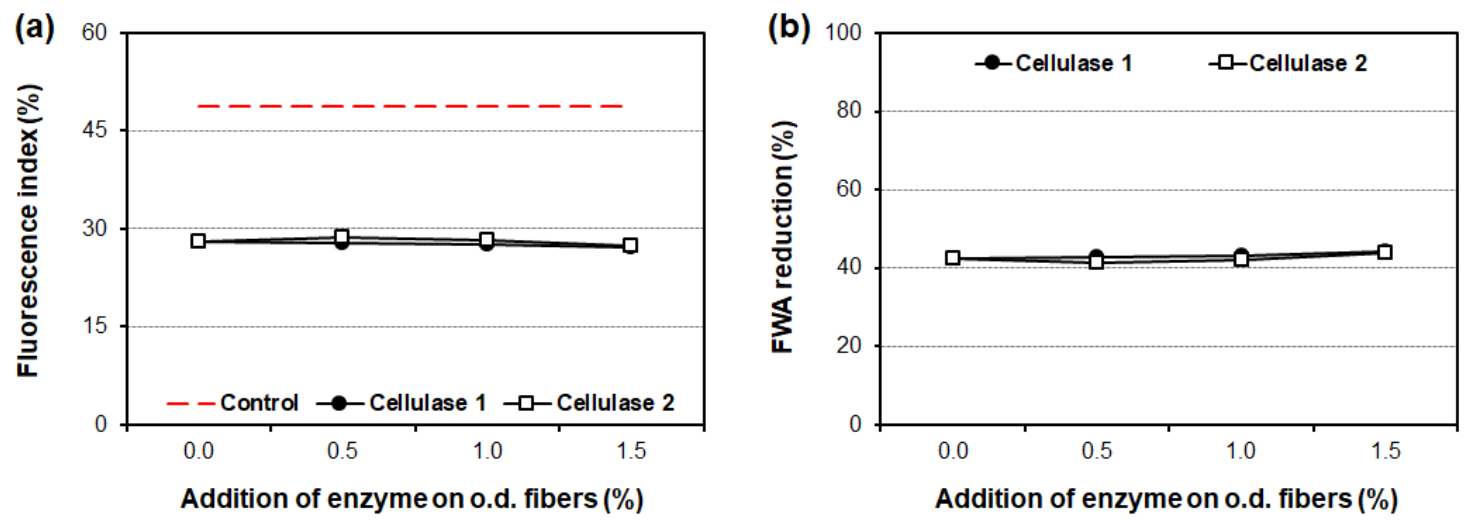

Fig. 6. Fluorescence index (a) and FWA reduction (b) of the handsheet made from the surfacesized paper with T-FWA after disintegration and cellulase treatment (where control indicates the surface-sized paper with $10 \%$ T-FWA)

Figure 6 shows the changes in the fluorescence index and the FWA reduction of the handsheet made from surface-sized paper with the addition of $10 \%$ T-FWA. Here, control indicates the surface-sized paper with $10 \%$ T-FWA. The initial fluorescence index of the surface-sized paper was about $49 \%$, and the fluorescence index of the handsheet decreased to $28 \%$ only after disintegration, indicating that disintegration led to $41 \% \mathrm{FWA}$ reduction. This is because a large amount of starch and T-FWA was detached from the surface-sized paper owing to shear force and dissolved into the aqueous phase (Shi et al. 2012; Lee et al. 2019). However, there was no further FWA reduction when cellulase treatment was performed after disintegration. This is because cellulase does not significantly affect starch dissociation and no chemical bonds are formed between T-FWA and cellulosic fibers (Walker and Hope 1963; Jayasekara and Ratnayake 2018; Lee et al. 2019). Figure 7 shows the fluorescence emission of the supernatant from surface-sized paper with T-FWA after disintegration and cellulase treatment. The initial fluorescence emission of the supernatant after disintegration was approximately 9, which is higher than that of the supernatant prepared with internally treated paper. The higher fluorescence emission indicates that T-FWA was separated from the surface-sized paper. However, cellulase treatment did not change the fluorescence emission of the supernatant, which is in agreement with the results of FWA reduction. Therefore, cellulase is an effective enzyme to control the removal of internal FWA (i.e., D-FWA) from recycled white papers.

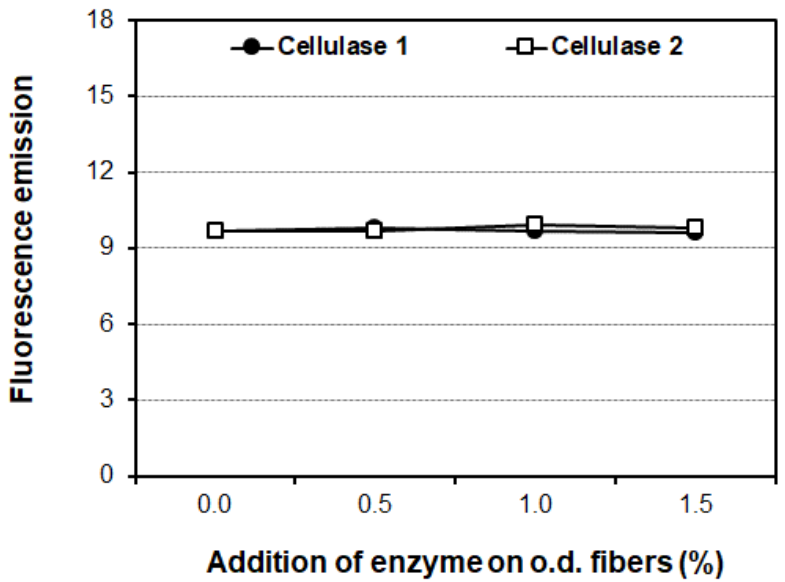

Fig. 7. Fluorescence emission of the supernatant from the surface-sized paper with T-FWA after disintegration and cellulase treatment 


\section{FWA Removal from Two Model Papers using Amylase}

Amylase is an important enzyme used in various industries and plays a major role in pulp and paper industry. Amylase is utilized to alter the molecular weight and viscosity of starch, which is used for surface sizing and coating of papers (Saini et al. 2017). In this study, the applicability of amylase to remove FWAs was evaluated.

Figure 8 shows the fluorescence index and FWA reduction of the handsheets made from internally treated paper with $1 \%$ D-FWA after disintegration and amylase treatment. The difference between the initial fluorescence index of the internal treated paper and that of the handsheet after disintegration was not significant. This result is similar to previous experimental results. Although the amylase treatment was performed, a decrease in the fluorescence index was not confirmed, and FWA reduction did not increase as a function of amylase addition.
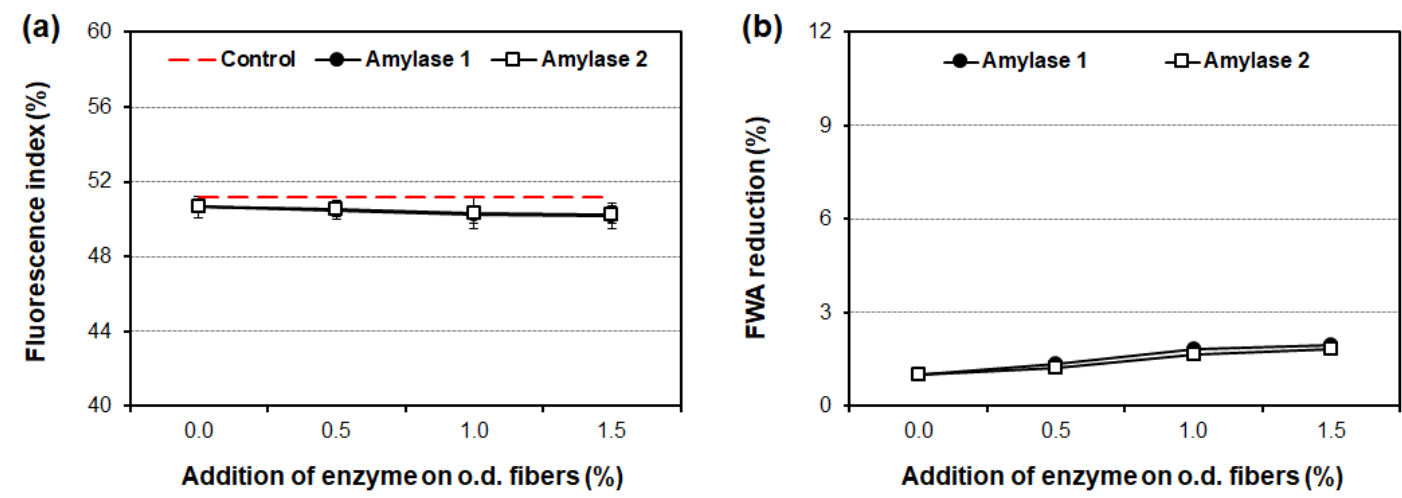

Fig. 8. Fluorescence index (a) and FWA reduction (b) of the handsheets from internally treated paper with D-FWA after disintegration and amylase treatment (where control indicates the internally treated model paper with $1 \% \mathrm{D}-\mathrm{FWA}$ )

Figure 9 shows the fluorescence emission of the supernatant from the internally treated paper with D-FWA after disintegration and amylase treatment. Amylase treatment did not change the fluorescence emission of the supernatant, which followed the same trend as that of the handsheet. Therefore, amylase is not effective for removing internal FWAs in the recycling process.

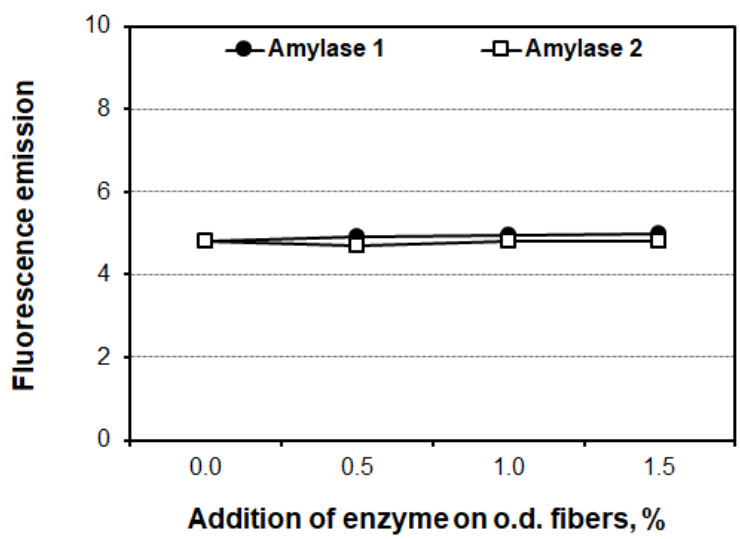

Fig. 9. Fluorescence emission of the supernatant from the internally treated paper with D-FWA after disintegration and amylase treatment

Figure 10 shows the fluorescence index and FWA reduction of the handsheet made from the surface-sized paper with T-FWA after disintegration and amylase treatment. There was a decrease of about $41 \%$ in the fluorescence index of the handsheet after 
disintegration, indicating that starch and T-FWA can separate more easily than D-FWA from the surface-sized paper by application of mechanical force. This result agrees with the previous experimental results. As the amylase treatment progressed after disintegration, the fluorescence index of the handsheet decreased, and the maximum FWA reduction was $65 \%$ for $1.5 \%$ amylase 2 . For the same percentage of amylase added, amylase 2 showed higher FWA reduction owing to its higher enzyme activity. The fluorescence emission of the supernatant increased linearly with amylase addition as shown in Fig. 11, because the amount of detached T-FWA in the supernatant increased. The fluorescence emission of the supernatant supported the T-FWA reduction by amylase treatment.
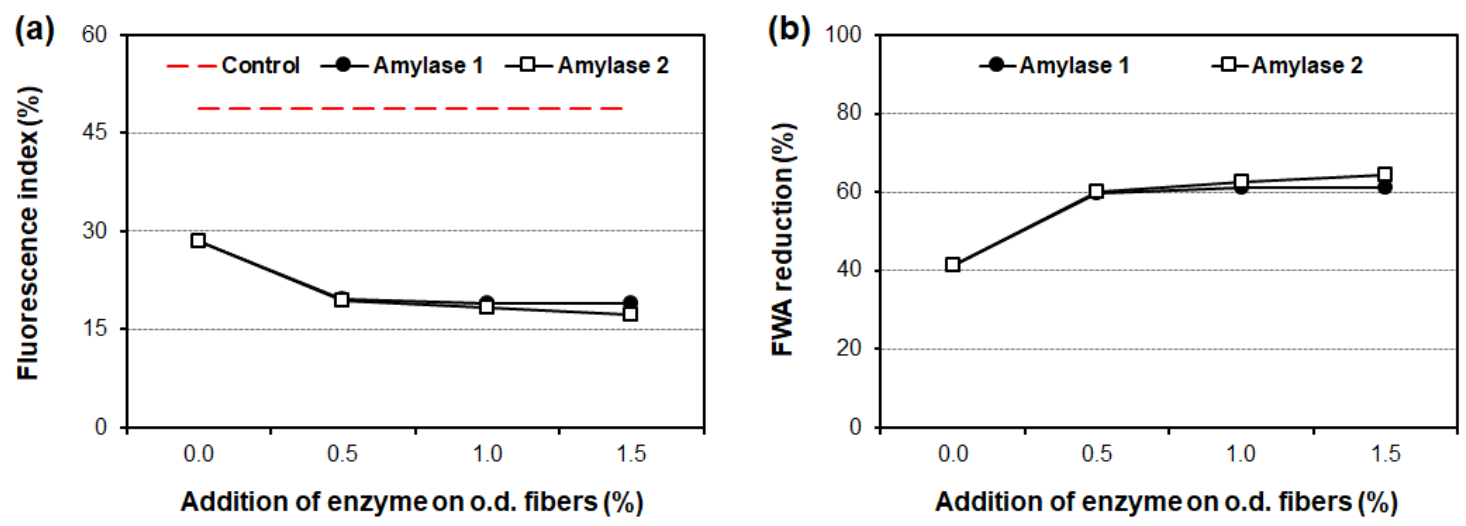

Fig. 10. Fluorescence index (a) and FWA reduction (b) of the handsheet made from the surfacesized paper with T-FWA after disintegration and amylase treatment (where control indicates the surface-sized paper with $10 \%$ T-FWA)

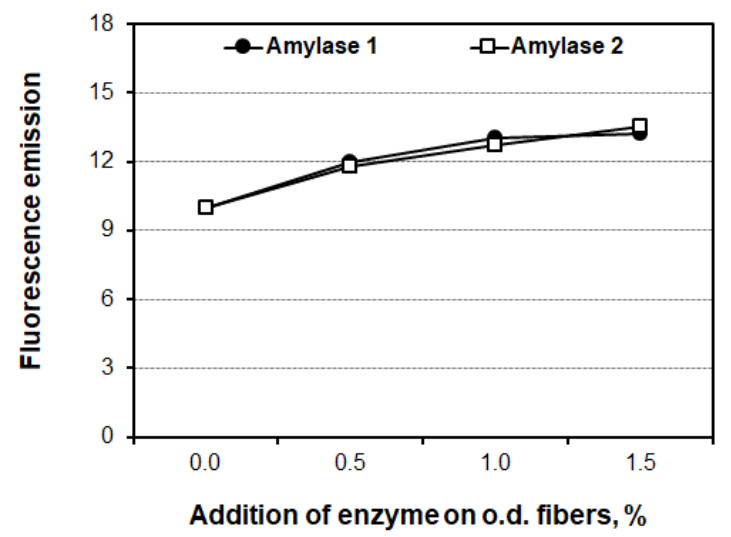

Fig. 11. Fluorescence emission of the supernatant of the stock prepared from the surface-sized paper after disintegration and amylase treatment

Figure 12 shows the mechanism of T-FWA detachment from recycled white papers using amylase. Alpha-amylase detaches the surface-sizing starch from the recycled white paper by degrading the a-D-1,4 glucosidic linkage of starch (Liu 2015; Glen 2018). T-FWA is present on the paper surface with starch and does not form hydrogen bonds with cellulosic fibers. Hence, T-FWA is extracted from the recycled white paper with degraded starch. Therefore, amylase is an effective enzyme to remove surface-sizing FWA (i.e., TFWA) from recycled white papers. 


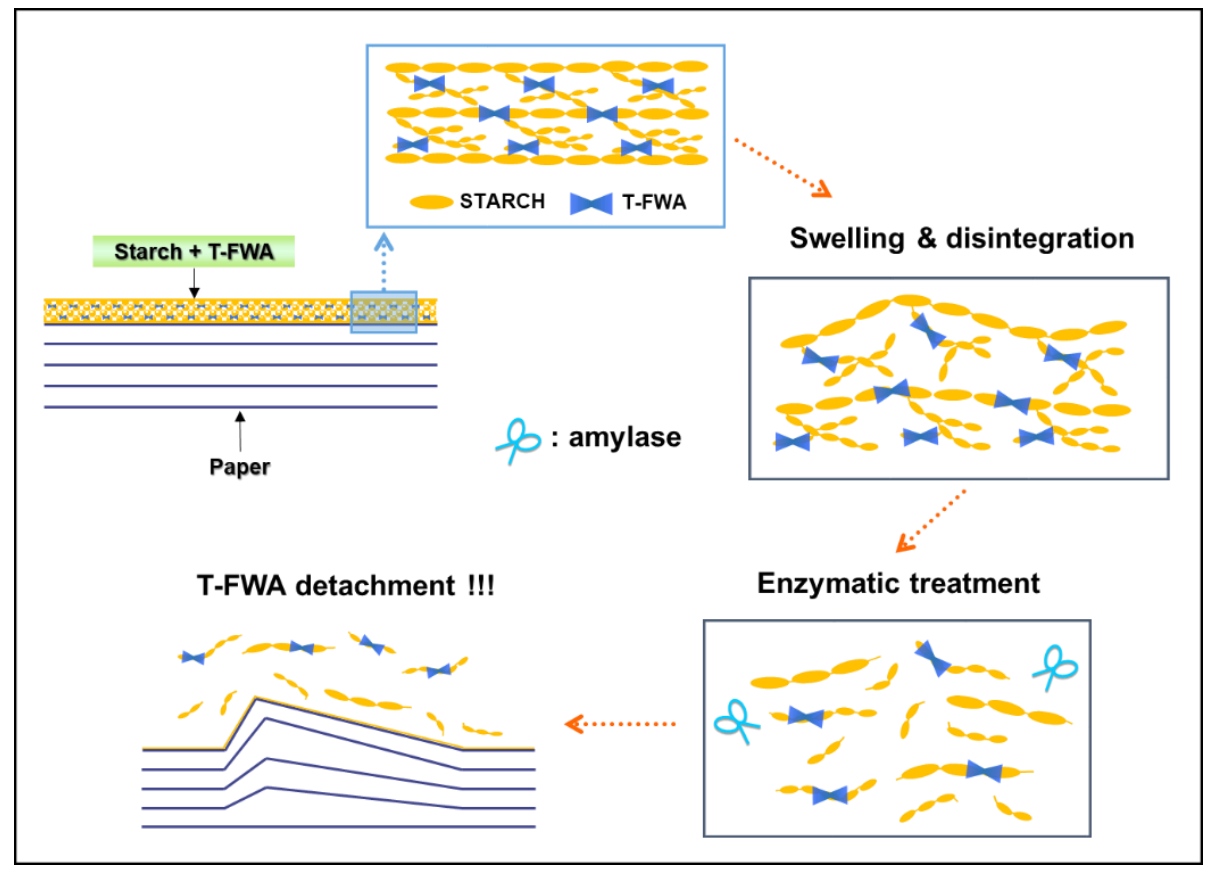

Fig. 12. Mechanism of T-FWA detachment from recycled white paper using amylase

\section{CONCLUSIONS}

1. Disulfonated fluorescence whitening agent (D-FWA) did not easily separate from internally treated paper when subjected to a disintegration process alone because it was strongly attached to the cellulosic fibers. Up to $8.1 \%$ of D-FWA was removed when the disintegration was preceded by enzymatic treatment with cellulase at relatively high activity. However, amylase could not separate D-FWA from the cellulosic fibers. Therefore, cellulase was found to have a low level of effectiveness for removing internal FWA (D-FWA).

2. A disintegration process separated about $41 \%$ of T-FWA, and up to $23 \%$ of T-FWA was additionally detached from surface-sized papers by enzymatic treatment with amylase at relatively high activity levels. Therefore, alpha-amylase is required to separate surface-sizing FWA (T-FWA) from recycled white papers.

\section{ACKNOWLEDGEMENTS}

This study was carried out by the Forest Service's Forest Convergence Specialist Training Project (Support for Forest Industry Characterization Research, FTIS Assignment No. 2020186A00-2022-AA02).

\section{REFERENCES CITED}

Buschmann, W. E. (2018). "Methods of optical brightening agent removal," U. S. Patent No. $15 / 658,709$.

Dainelli, D. (2008). "Recycling of food packaging materials: An overview," In: Environmentally Compatible Food Packaging, E. Chiellini (ed.), Woodhead publishing, Cambridge, UK, pp. 294-325. DOI: 10.1533/9781845694784.2.294 
Crini, G., and Lichtfouse, E. (2018). "Advantages and disadvantages of techniques used for wastewater treatment," Environmental Chemistry Letters 17, 145-155. DOI:10.1007/s10311-018-0785-9

Glen, F. (2018). "Starch in brewing applications," In: Starch in Food, M. Sjöö and L. Nilsson (eds.), Woodhead publishing, Cambridge, UK, pp. 633-659. DOI: 10.1016/B978-0-08-1-100868-3.00016-0

Jayasekara, S., and Ratnayake, R. (2018). "Microbial cellulases: An overview and applications," In: Cellulose, A. R. Pascual and M. E. Eugenio Martin (eds.), IntechOpen, London, UK, pp. 3-10. DOI: 10.5772/intechopen.84531

Jeong, J. S. (2016). 2016 Wood Supply Performance Reports, Department of Forest Materials, Korea Forest Service, Daejeon, Republic of Korea.

Jiang, D., Chen, L., Fu, W., and Qiu, H. (2015). "Simultaneous determination of 11 fluorescent whitening agents in food-contact paper and board by ion-pairing highperformance liquid chromatography with fluorescence detection," Journal of Separation Science 38(4), 605-611. DOI:10.1002/jssc.201401110

Kim, E. H., Lee, J. Y., Kim, C. H., and Park, T. U. (2017). "Effect of carrier chemicals on the optical properties of paper surface-sized with fluorescent whitening agents," BioResources 12(2), 2982-2990. DOI: 10.15376/biores.12.2.2982-2990

Lakowicz, J. R., and Weber, G. (1973). "Quenching of fluorescence by oxygen. A probe for structural fluctuations in macromolecules," Biochemistry 12(21), 4161-4170. DOI: $1031021 / \mathrm{bi00745a020}$

Lee, J. Y., Kim, C. H., Jo, H. M., Kim, K. M., and Kim, S. H. (2019). "Effect of recycling number on the fluorescence reduction of fluorescent whitening agents in white wastepapers," Journal of Korea TAPPI 51(2), 49-57. DOI: 10.7584/JKTAPPI.2019.04.51.2.49

Lee, J. Y., Kim, C. H., Park, J. H., Sung, Y. J., Heo, Y. J., Kim, Y. H., and Kim, Y. O. (2015). "Analysis of the behavior of fluorescent whitening agents in recycling process of white ledger," Journal of Korea TAPPI 47(1), 52-58. DOI: 10.7584/ktappi.2015.47.1.05

Lee, J. Y., Lee, H. L., Lim, H. W., and Yoon, H. J. (2008). "Removal of fluorescent whitening agents from recycled fibers using enzyme," Nordic Pulp \& Paper Research Journal 23(1), 19-23. DOI: 10.3183/npprj-2008-23-01-p019-0232

Lee, J. Y., Youn, H. J., and Lee, H. L. (2012). "Fundamental study for quantitive analysis of the fluorescent whitening agent (FWA) content of paper and process water," BioResources 7(1), 315-325. DOI: 10.15376/biores.7.1.0315-0326

Lee, S. B., Shin, H. S., Ryu, D. D. Y., and Mandels, M. (1982). "Adsorption of cellulose: Effect of physicochemical properties of cellulose on adsorption and rate of hydrolysis," Biotechnology and Bioengineering 24, 2137-2153. DOI: 10.1002/bit.260241003

Lee, W. T. (2009). "Ozone process technology trend," Korea Environmantal Industry and Technology Institute, KEITI, Seoul, Republic of Korea.

Liu, D. (2015). “Aeromonas,” in: Molecular Medical Microbiology, Tang, Y. W., Sussman, M., Liu, D., Poxton, L., and Schwartzman, J (eds.), Academic Press, Massachusetts, USA, Ch. 61, DOI: 10.1016/B978-0-12-397169-2.00061-5

Pauksta, M. P. (1995). “A current perspective on the chlorine debate," TAPPI Journal 78(7), 63-65.

Perng, Y. S., Wang, I. C., and Chang, C. P. (2015). "Effect of co-binders for coating on the performance of fluorescent optical brightening agents," Cellulose Chemistry and Technology 49(2), 209-218.

Presas, T., and Pesonen, J. (2013). CEPI Sustainability Report 2013, Confederation of European Paper Industries, Brussels, Belgium. 
Rahikainen, J., Ceccherini, S., Molinier, M., Holopainen-Mantila, U., Reza, M., Väisänen, S., Puranen, T., Kruus, K., Vuorinen, T., Maloney, T., Suurnäkki, A., and Grönqvist, S. (2019). "Effect of cellulase family and structure on modification of wood fibres at high consistency," Cellulose 26(8), 5085-5103. DOI: 10.1007/s10570019-02424-x

Saini, R., Saini, H. S., and Dahiya, A. (2017). "Amylases: Characteristics and industrial applications," Journal of Pharmacognosy and Phytochemistry 6(4), 1865-1871. DOI: 10.22271/phyto

Shadkami, F., Helleur, R., and Sithole, B. B. (2011). "The analysis of optical brightening agents in paper samples using liquid chromatography with high-resolution mass spectrometry," Journal of Wood Chemistry and Technology 31(1), 42-57. DOI: 10.1080/022773811003725695

Shi, H., Liu, H., Ni, Y., Yuan, Z., Zou, X., and Zhou, Y. (2012). "Review: Use of optical brightening agents (OBAs) in the production of paper containing high-yield pulps," BioResources 7(2), 2582-2591. DOI: 10.15376/biores.7.2.2582-2591

TAPPI T205 sp-06 (2006). "Forming handsheets for physical tests of pulp," TAPPI Press, Atlanta, GA, USA.

Walker, G. J., and Hope, P. M. (1963). "The action of some $\alpha$-amylases on starch granules," Biochemical Journal 86(3), 452-462. DOI: 10.1042/bj0860452

Zhao, X., Yang, D., Pang, Y., and Shen, X. (2020). "Quaternary ammonium salt ion pair reagent sensitizing for determination of fluorescence whitening agent 85 in paper food packaging," Spectrochimica Acta Part A: Molecular and Biomolecular Spectroscopy 231, 118125. DOI: 10.1016/j.saa.2020.118125

Article submitted: August 17, 2020; Peer review completed: September 13, 2020; Revised version received: September 22, 2020; Accepted: October 12, 2020; Published: October 27, 2020.

DOI: 10.15376/biores.15.4.9462-9473 